\title{
Carbon and nitrogen dynamics in the coastal Japan Sea inferred from 15 years of measurements of stable isotope ratios of Calanus sinicus
}

Ken-ichi Nakamura ${ }^{1,2}$, Atsushi Nishimoto ${ }^{3}$, Saori Yasui-Tamura ${ }^{1,4}$, Yoichi Kogure ${ }^{1}$, Misato Nakae ${ }^{1}$, Naoki Iguchi ${ }^{1}$, Haruyuki Morimoto ${ }^{1}$, Taketoshi Kodama ${ }^{5}$

5 'Fisheries Resources Institute, Japan Fisheries Research and Education Agency, Niigata, 951-8121, Japan

${ }^{2}$ Present address: Kokusai Kogyo Co. Ltd., Tokyo, 102-0085, Japan

${ }^{3}$ Fisheries Technology Institute, Japan Fisheries Research and Education Agency, Yokohama, 236-8648, Japan

${ }^{4}$ Present address: Department of Ocean Sciences, Tokyo University of Marine Science and Technology, Tokyo, 108-8477, Japan

$10{ }^{5}$ Fisheries Resources Institute, Japan Fisheries Research and Education Agency, Yokohama, 236-8648, Japan

Correspondence to: Taketoshi Kodama (takekodama@affrc.go.jp)

Abstract. Human activities have caused sometimes dramatic changes to the marine environment globally and locally during the last half century. We hypothesized that the carbon and nitrogen stable isotope ratios $\left(\delta^{13} \mathrm{C}\right.$ and $\left.\delta^{15} \mathrm{~N}\right)$ of the copepod Calanus sinicus, one of the dominant secondary producers of North Pacific coastal waters, would record anthropogenic impacts on the

15 coastal environment of the Japan Sea. We monitored these isotope ratios during the spring at four stations in the Japan Sea from 2006 to 2020 . The $\delta^{13} \mathrm{C}$ values ranged from $-24.7 \%$ to $-15.0 \%$ and decreased from the spring bloom (February/March) to the post-bloom (June/July). This monthly variation was attributed to changes in both the physiology of $C$. sinicus and phytoplankton $\delta^{13} \mathrm{C}$. The negative correlation between the $\delta^{13} \mathrm{C}$ values of $C$. sinicus and their carbon:nitrogen ratios reflected lipid accumulation by the copepods; high $\delta^{13} \mathrm{C}$ values were associated with high sea surface chlorophyll $a$ concentrations. The

$20 \delta^{15} \mathrm{~N}$ values ranged from $2.8 \%$ to $8.8 \%$. The tendency of the $\delta^{15} \mathrm{~N}$ values to increase from the bloom to post-bloom was attributable to an increase of the $\delta^{15} \mathrm{~N}$ of the phytoplankton associated with nitrate depletion and Rayleigh fractionation. These monthly changes were synchronized among the four stations, but $\delta^{13} \mathrm{C}$ and $\delta^{15} \mathrm{~N}$ differed significantly between stations. Interannual variations were statistically significant, but there were no significant monotonic trends. Interannual variations differed between $\delta^{13} \mathrm{C}$ and $\delta^{15} \mathrm{~N}$ as well as among stations. These results suggest that local conditions rather than global-scale trends were the primary determinants of elemental cycles in this coastal ecosystem.

\section{Introduction}

The ecosystem services provided by coastal areas are more valuable than those provided by any other biome on Earth (Costanza et al., 1997). Coastal ocean ecosystems are important for human activities and have been greatly changed as a result of those activities (Halpern et al., 2008; Doney, 2010). The coastal waters of Japan are known to be among the areas most impacted by

30 human activities (Halpern et al., 2008). The Japan Sea (the Sea of Japan), which has been greatly impacted by human activities and global climate change, is considered to be an oceanic microcosm of the changing global ocean (Chen et al., 2017). Monotonic changes have been detected in the chemical environment of the coastal area of the Japan Sea as well as of the global 
https://doi.org/10.5194/os-2021-74

Preprint. Discussion started: 19 August 2021

ocean (Ishizu et al., 2019; Ono, 2021; Kodama et al., 2016). In the surface waters of the Japan Sea, pH and concentrations of phosphate and dissolved oxygen have been decreasing during the last few decades (Ishizu et al., 2019; Ono, 2021; Kodama et al., 2016), whereas anthropogenic inputs of nitrogen from the atmosphere to the Japan Sea have been increasing (Kitayama et al., 2012).

Stable isotope ratios of carbon and nitrogen have been employed as tools to discern both elemental cycles and environmental changes in marine ecosystems (Ohman et al., 2012; Lorrain et al., 2020; Ren et al., 2017). During the 21 st century, the ${ }^{13} \mathrm{C}:{ }^{12} \mathrm{C}$ carbon isotopic ratio of tuna has been rapidly decreasing as a linear function with time, and the rate of decrease has been faster than would be expected based on the Suess effect and the increase of anthropogenic carbon emissions (Gruber et al., 1999). It has thus been hypothesized that lower-trophic-level ecosystems have changed on a global scale (Lorrain et al., 2020). The input of anthropogenic nitrogen from the atmosphere to the ocean has been increasing (Duce et al., 2008), and in the marginal seas of East Asia, the ${ }^{15} \mathrm{~N}:{ }^{14} \mathrm{~N}$ nitrogen isotopic ratio of the organic matter bound in coral skeletons has decreased with the increase of anthropogenic nitrogen deposition (Ren et al., 2017).

45 Stable isotope ratios are often used as metrics of the trophic positions of organisms in ecosystems (Aita et al., 2011) and as indicators of changes in the chemical environment. The ${ }^{15} \mathrm{~N}:{ }^{14} \mathrm{~N}$ ratio increases at successively higher tropic levels in a food chain. In this study, we focused on Calanus sinicus, one of the dominant copepod species in the coastal waters of the western North Pacific (Uye, 2000), including the Japan Sea (Kodama et al., 2018a). Copepods of the genus Calanus are the major component of the macrozooplankton in shelf and coastal ecosystems outside the tropics, and they are the major source of nutrition for pelagic fish (Uye, 2000). Coastal areas of the Japan Sea are spawning and nursery grounds for Japanese sardine (Sardinops melanosticta), Japanese anchovy (Engraulis japonicus), and Pacific bluefin tuna (Thunnus orientalis) (Nishida et al., 2020; Furuichi et al., 2020; Ohshimo et al., 2017), and the larvae of these species prey on both the larval and adult stages of C. sinicus (Hirakawa et al., 1997; Hirakawa and Goto, 1996; Kodama et al., 2017a). Calanus sinicus therefore plays an important role as a major component of the second trophic level in the Japan Sea.

55 Studies of the long-term carbon and nitrogen dynamics in the Japan Sea (Ishizu et al., 2019; Ono, 2021; Kodama et al., 2016) have suggested that monotonic changes are likely to occur throughout the coastal ecosystem of the Japan Sea as the climate changes on a global scale. In fact, the muscle of small pelagic fish in the Japan Sea and the East China Sea from 1996 to 2019 shows that annual mean ${ }^{13} \mathrm{C}:{ }^{12} \mathrm{C}$ and ${ }^{15} \mathrm{~N}:{ }^{14} \mathrm{~N}$ are monotonically decreased $0.08 \%$ year ${ }^{-1}$ and $0.05 \%$ year ${ }^{-1}$, respectively (Ohshimo et al., in press). However, spatial heterogeneity of the chemical environment and ecosystem of the coastal Japan Sea have also been reported. For example, long-term trends in the amounts of anthropogenic inputs are not spatially uniform: since 1997 total nitrogen inputs from rivers to Toyama Bay have been decreasing (Terauchi et al., 2014b) and those to Wakasa Bay have been increasing (Sugimoto and Tsuboi, 2017). Such differences suggest that interannual variations of environmental conditions are unlikely to be spatially homogeneous. Evaluations of local marine ecosystems and comparisons based on observations will therefore be necessary to understand changes of the coastal environment and ecosystems of the Japan Sea, and thus to achieve Sustainable Development Goal 14 of the United Nations. The goal of this study was therefore to understand 
https://doi.org/10.5194/os-2021-74

Preprint. Discussion started: 19 August 2021

the spatiotemporal variations of lower-trophic levels in the coastal area of the Japan Sea through analysis of the carbon and nitrogen stable isotope ratios of $C$. sinicus.

\section{Materials and methods}

\subsection{Onboard observations}

70 Onboard observations were conducted from pre-bloom to post-bloom in 2006-2020 during cruises of the R/V Mizuho-Maru, R/V Yoko-Maru (Japan Fisheries Research and Education Agency), and R/V Dai-Roku Kaiyo-Maru (Kaiyo Engineering Co., Ltd.) in the territorial waters of Japan in the Japan Sea, a marginal sea of the western North Pacific (Fig. 1). Four stations for collection of stable isotope samples were chosen: in Toyama Bay (TB), Iida Bay (IB), north of the Noto Peninsula (NN), and Wakasa Bay (WB). These four stations are among 26 stations described in a previous study (Kodama et al., 2018a) that reported

75 a clear west-east gradient of zooplankton community structure in this area during the month of May. Station (stn) TB was located near the mouths of two rivers (the Sho River and Oyabe River, Fig. 1), and stn WB was in an area of restricted circulation in Wakasa Bay. The cruises were conducted during four time intervals: 1) the end of February and/or the beginning of March (described as March), 2) the end of April, 3) the middle or end of May, and 4) the end of June or beginning of July (described as June) (Fig. 1c). The March cruise corresponded to the early stage of the spring phytoplankton bloom, the April

80 cruise was during the late stage of the bloom, and the May and June cruises occurred during post-bloom conditions according to Kodama et al. (2018b). The observations after 2015 were conducted only in April and May (Fig. 1c).

Copepods for stable isotope analyses were collected by towing a Bongo net (500- $\mu \mathrm{m}$ mesh and 70 -cm mouth diameter) obliquely at $0.5 \mathrm{~m} \mathrm{~s}^{-1}$ from a depth of 75 or from $10 \mathrm{~m}$ above the bottom to the surface at each station. Collected samples were frozen and preserved at a temperature below $-20^{\circ} \mathrm{C}$ until sorting at an onshore laboratory. Vertical profiles of temperature,

85 salinity, and chlorophyll $a$ concentrations were measured by using a conductivity-temperature-depth (CTD) sensor (Seabird, SBE9plus or SBE19plus) with an in vivo chlorophyll fluorescence sensor from a depth of $200 \mathrm{~m}$ to the surface. Temperature and salinity of the sensors were calibrated by the manufacturer every year. The surface seawater was sampled with a bucket for measurement of sea surface temperature (SST), sea surface salinity (SSS), and sea surface chlorophyll $a$ concentration (SSC). SST and SSS were measured with a calibrated mercury thermometer and a salinometer (Autosal, Guildline Instruments), 90 respectively. For measurement of chlorophyll $a$ concentrations, particles in $300 \mathrm{ml}$ of water were collected on a glass fiber filter (GF/F, Whatman) and the pigments were extracted with $N, N$-dimethylformamide. The chlorophyll $a$ concentrations were estimated based on the fluorescence of the extract, which was measured with a fluorometer (10-AU, Turner Designs) (HolmHansen et al., 1965). The chlorophyll fluorescence sensor was calibrated using these discrete samples during each cruise. Nutrient concentrations at the surface were measured during some cruises after 2015. The procedures used for the nutrient 95 analyses have been described by Kodama et al. (2015). 
https://doi.org/10.5194/os-2021-74

Preprint. Discussion started: 19 August 2021

\subsection{Stable isotope analyses}

The frozen-preserved Bongo net samples were thawed at room temperature. From every single thawed sample, 7-14 individuals of Calanus sinicus (Copepoda; Calanoida) adults or copepodite stage V were sorted as quickly as possible to avoid alteration of their condition under the dissecting microscope. We collected 1-8 C. sinicus individuals from 94 net samples; in some samples, we could not find enough $C$. sinicus individuals for stable isotope analysis. The sorted copepods were dried at $60^{\circ} \mathrm{C}$ in a drying oven for $36-48 \mathrm{~h}$. A total of 274 dried samples were wrapped in a tin disk. Table 1 provides details about the numbers of samples. At some stations, several samples were prepared, and we treated each sample separately, i.e., we measured the stable isotope ratios of every sample, and we did the statistical analyses without averaging data from the same station. The carbon and nitrogen stable isotope ratios of the samples were measured with a stable isotope ratio mass spectrometer (IsoPrime100; Elementar) coupled with an elemental analyzer (vario MICRO cube; Elementar). Stable isotope ratios of carbon and nitrogen were calculated as the per mil (\%) deviations from the corresponding standards using the following equation:

$\delta^{13} \mathrm{C}$ or $\delta^{15} \mathrm{~N}=\left[\left(R_{\text {sample }} / R_{\text {standard }}\right)-1\right] \times 1000$

where $R$ is the ${ }^{13} \mathrm{C} /{ }^{12} \mathrm{C}$ or ${ }^{15} \mathrm{~N} /{ }^{14} \mathrm{~N}$ ratio. The standards for carbon and nitrogen were L-alanine, and the references were Pee Dee Belemnite and atmospheric $\mathrm{N}_{2}$, respectively. The precisions of the analyses were within $0.2 \%$ for both $\delta^{13} \mathrm{C}$ and $\delta^{15} \mathrm{~N}$. Based on the precision of analyses of $\mathrm{L}$-alanine, the $\delta^{13} \mathrm{C}$ and $\delta^{15} \mathrm{~N}$ values for each sample were rounded off to one decimal place.

The amounts of carbon and nitrogen in each sample were also recorded, but that information was missing for 69 samples when the database was created. The carbon:nitrogen ratio ( $\mathrm{C} / \mathrm{N}$ ratio) of $C$. sinicus was calculated using the $\mathrm{C} / \mathrm{N}$ ratios in the database.

\section{$115 \quad 2.3$ Statistical analyses}

The relationships between the $\delta^{13} \mathrm{C}$ and $\delta^{15} \mathrm{~N}$ of $C$. sinicus and environmental parameters were analyzed using general linear models (GLMs) with the linear link function in R software (R Core Team, 2020). The structures of the GLMs were based on concepts articulated by Kodama et al. (2021). The $\delta^{13} \mathrm{C}$ and $\delta^{15} \mathrm{~N}$ errors were assumed to be normal distributions, and explanatory variables were expressed as linear functions in the GLMs, with the exception of SSC, which was log transformed.

120 Two types of GLMs were applied as follows:

$\delta \mathrm{X} \sim \operatorname{poly}(\mathrm{SST}, 2)+\operatorname{poly}(\operatorname{logSSC}, 2)+\operatorname{poly}(\mathrm{SSS}, 2)+f(\mathrm{stn})$

$\delta \mathrm{X}_{\mathrm{stn}} \sim f($ year $)+f($ month $)$

where $\delta \mathrm{X}$ and stn represent the target $\delta^{13} \mathrm{C}$ or $\delta^{15} \mathrm{~N}$ and station (WB, NN, IB and TB), respectively. The arguments of the $f$ functions were categorical variables used to simulate nonlinear relationships. The second argument of the poly functions (i.e.,

125 2) indicates that the first argument was incorporated into a quadratic expression in the model, i.e., dome-shaped responses were included in the models.

Equation (2) was intended to consider environmental and geographical effects, and Eq. (3) was intended to take into consideration monthly and interannual variations at every station $\left(\delta \mathrm{X}_{\mathrm{stn}}\right)$. We could theoretically have evaluated monthly and 
https://doi.org/10.5194/os-2021-74

Preprint. Discussion started: 19 August 2021

interannual variations at every station using interaction terms such as $f$ (month): $f($ year): $f($ stn) in Eq. (2), but when we included those interaction terms, the generalized variance inflation factors (GVIFs) became infinite. We therefore used two models. Environmental parameters were not included in Eq. (3) because we wanted to calculate climatological values that would reflect monthly and interannual variations of environmental parameters. The times of sample collection were to some extent opportunistic (Fig. 1C), and thus comparisons of simple mean values could be misleading if interannual or monthly variations were significant. An interaction term $f($ month): $f($ year) was considered in Eq. (3), but because the GVIFs were infinite, we did not include an interaction term in the model. The explanatory variables in the final version of Eq. (2) were determined on the basis of values of GVIFs and Akaike information criteria (AICs). We required that the GVIFs of explanatory variables be less than 10, and the model with the smallest AIC was accepted as the final model.

The "gglsmean" function in the "ggeffects" package (Lüdecke, 2018) was used to calculate the least squares mean (lsmean) values and standard errors based on the AIC-selected GLMs and to visualize the effect of the explanatory variables on the $\delta^{13} \mathrm{C}$ or $\delta^{15} \mathrm{~N}$ values. When the categorical variables (i.e., month and year) remained in the least-AIC models, their values were fixed for purposes of calculating the lsmean values. We note that we considered the nonlinear effects of environmental variables using generalized additive models (GAMs) instead of Eq. (2). However, the AIC values were not greatly improved in the GAMs. In this study, we have therefore reported only the GLM results. All the data and program code are in Mendeley data (Nakamura et al., 2021).

\section{Results}

\subsection{Environmental factors}

SST increased from March to June at every station (Fig. 2a). The SST at WB, the westernmost station, was the highest among the four stations on every cruise. The SST ranges were $8.8-23.1^{\circ} \mathrm{C}, 9.5-21.9^{\circ} \mathrm{C}, 9.3-23.2^{\circ} \mathrm{C}$, and $10.1-23.4^{\circ} \mathrm{C}$ at stations $\mathrm{TB}$, IB, NN, and WB, respectively. SSS was low at the TB station (Fig. 2b). In this less-saline water, the nitrate concentration was several micromoles even in June, whereas it was depleted at the other three stations (data not shown). SSS was highest in May at the other three stations. Variations of SSC at TB differed from those at the other stations. SSC was higher at TB than at the other stations during every month. In addition, SSC at TB was higher in June than in May (Fig. 2c). The SSC values fell in the ranges $0.02-7.45,0.08-5.46,0.05-9.07$, and $0.08-6.60 \mu \mathrm{g} \mathrm{L}^{-1}$ at $\mathrm{TB}, \mathrm{IB}, \mathrm{NN}$, and $\mathrm{WB}$, respectively.

\subsection{Stable isotope ratios of $\mathrm{C}$ and $\mathrm{N}$}

155 The means \pm standard deviations of all of the $C$. sinicus $\delta^{13} \mathrm{C}$ and $\delta^{15} \mathrm{~N}$ values were $-20.7 \pm 1.8 \%$ o $(-24.7 \%$ o to $-15.0 \%$ and $6.9 \pm 1.2 \%$ o (2.8-8.8\%o), respectively. Significant monthly variations were observed for both $\delta^{13} \mathrm{C}$ and $\delta^{15} \mathrm{~N}$ at every station (ANOVA, $p<0.001$, Fig. 3). The highest $\delta^{13} \mathrm{C}$ values were observed in March at all four stations (TB: $-17.5 \pm 2.1 \%$; IB: $-18.7 \pm 1.1 \%$; NN: $18.7 \pm 0.9 \%$; and WB: $-18.5 \pm 1.1 \%$ ). The monthly mean $\delta^{13} \mathrm{C}$ values decreased from March to May at 
https://doi.org/10.5194/os-2021-74

Preprint. Discussion started: 19 August 2021

all four stations, although there was only one sample at WB in May (Fig. 3). In June, monthly mean $\delta^{13} \mathrm{C}$ values were similar

to those in May, except at NN. The mean $\delta^{13} \mathrm{C}$ at NN was significantly lower in May $(-22.4 \pm 2.2 \%)$ than in June $(-21.2 \pm$ $1.3 \%$ ) (ANOVA with Tukey's HSD test, $p=0.028$ ). The monthly mean values were significantly different among stations in April and March (ANOVA, $p<0.006$ ). In all four months, the $\delta^{13} \mathrm{C}$ at $\mathrm{NN}$ was the lowest among the four stations, and there were significant differences between the $\delta^{13} \mathrm{C}$ values at WB and at NN in April and between those at TB and at NN in May (ANOVA with Tukey's HSD test, $p<0.006$ ).

165 The lowest monthly mean $\delta^{15} \mathrm{~N}$ was observed in March at all four stations (TB: $5.1 \pm 0.8 \%$; IB: $5.1 \pm 1.4 \%$; NN: $5.6 \pm 1.3 \%$; and WB: $4.5 \pm 1.0 \%$ ). The $\delta^{15} \mathrm{~N}$ values were significantly elevated in April (TB: $7.4 \pm 1.3 \%$; IB: $7.3 \pm 0.5 \%$; NN: $7.5 \pm 0.5 \%$; and WB: $7.0 \pm 0.7 \%$ ), and they were stable from April to June (ANOVA with Tukey’s HSD test, $p>0.2$ ) at all four stations (Fig. 3b). The differences of the monthly values among stations were significant during all four months (ANOVA, $p<0.037$ ): monthly $\delta^{15} \mathrm{~N}$ values at $\mathrm{NN}$ were highest among the four stations in every month. In March, April, and June, the $\delta^{15} \mathrm{~N}$ values were significantly lower at WB than at NN (ANOVA with Tukey's HSD test, $p<0.03$ ), but there were no significant differences between other pairs of stations. In May, the values were significantly lower at TB and IB than at NN (ANOVA with Tukey's HSD test, $p<0.003$ ).

There were significant linear relationships between the $\delta^{13} \mathrm{C}$ and $\delta^{15} \mathrm{~N}$ values and SST, logarithm-transformed SSC, and SSS, but the nature of the relationships differed between $\delta^{13} \mathrm{C}$ and $\delta^{15} \mathrm{~N}$ (Fig. 4). The Pearson's correlation coefficient was positive between $\delta^{13} \mathrm{C}$ and logarithm-transformed SSC $(p<0.001 ; r=0.478)$, negative between $\delta^{13} \mathrm{C}$ and SST $(p<0.001 ; r=-0.564)$, and negative between $\delta^{13} \mathrm{C}$ and SSS ( $\left.p<0.001 ; r=-0.202\right)$ (Fig. 4a-c). In contrast, the Pearson's correlation coefficient was positive between $\delta^{15} \mathrm{~N}$ and both SST $(p<0.001 ; r=0.361)$ and SSS $(p<0.001 ; r=0.228)$, and it was negative between $\delta^{15} \mathrm{~N}$ and logarithm-transformed SSC ( $p<0.001 ; r=-0.298)$ (Fig. 4e-g). When an outlier value of SSS was removed (SSS was 28 in March at TB), the correlations with SSS were still significant. Although there were relatively few $\mathrm{C} / \mathrm{N}$ ratios of $C$. sinicus,

180 they were negatively and positively correlated with $\delta^{13} \mathrm{C}$ and $\delta^{15} \mathrm{~N}$, respectively (both $p<0.001$, Fig. 5d, h). The monthly means of the $\mathrm{C} / \mathrm{N}$ ratios of $C$. sinicus were high during April at every station.

\subsection{Generalized linear models}

In the least-AIC models with Eq. (2), SSS was removed from the full model in the cases of both $\delta^{13} \mathrm{C}$ and $\delta^{15} \mathrm{~N}$. Thus, the following equations were the least-AIC models.

$185 \delta^{13} \mathrm{C} \sim-17.6( \pm 1.85) \times \mathrm{SST}+8.05( \pm 1.32) \times \mathrm{SST}^{2}+2.20( \pm 1.83) \times \operatorname{logSSC}+4.28( \pm 1.42) \times(\operatorname{logSSC})^{2}+f(\operatorname{stn})$

$\delta^{15} \mathrm{~N} \sim 9.42( \pm 1.47) \times \mathrm{SST}-7.08( \pm 1.04) \times \mathrm{SST}^{2}+1.15( \pm 1.44) \times \operatorname{logSSC}-3.42( \pm 1.12) \times(\operatorname{logSSC})^{2}+f(\operatorname{stn})$

The coefficients of determination ( $r^{2}$ values) of the least-AIC $\delta^{13} \mathrm{C}$ and $\delta^{15} \mathrm{~N}$ models were 0.526 and 0.369 , respectively. The effects of all variables were significant, and both SST and $\operatorname{logSSC}$ remained in the quadratic formulation of the models. 
https://doi.org/10.5194/os-2021-74

Preprint. Discussion started: 19 August 2021

The least-AIC models produced convex graphs of $\delta^{13} \mathrm{C}$ as a function of SST or $\operatorname{logSSC}$ (Fig. 5a, b). The minima of the $\delta^{13} \mathrm{C}$ values occurred at approximately $18^{\circ} \mathrm{C}$ and $1 \mu \mathrm{g} / \mathrm{L}$ in the case of SST and the SSC concentration, respectively (Fig. 5a, b). Inter-station comparisons indicated that the $\delta^{13} \mathrm{C}$ values were $0.6-1.1 \%$ higher at $\mathrm{WB}$ and TB than at IB and $\mathrm{NN}$ (Fig. $5 \mathrm{c}$ ). The responses of $\delta^{15} \mathrm{~N}$ were the mirror images of the $\delta^{13} \mathrm{C}$ responses (Fig. $5 \mathrm{~d}$, e). The least-AIC models produced concave graphs of $\delta^{15} \mathrm{~N}$ as a function of SST or $\operatorname{logSSC}$ (Fig. $5 \mathrm{~d}$, e). The $\delta^{15} \mathrm{~N}$ maxima occurred at approximately $18^{\circ} \mathrm{C}$ and $1 \mu \mathrm{g} \mathrm{L}{ }^{-1}$ in the case of SST and SSC (Fig. 5d, e). Inter-station comparisons indicated that $\delta^{15} \mathrm{~N}$ values were $0.4-8.5 \%$ lower at WB and TB than at IB and NN (Fig. 5f).

The GLM described by Eq. (3) indicated that there were significant interannual and monthly variations of $\delta^{13} \mathrm{C}$ (Fig. 6). The monthly variations of lsmean $\delta^{13} \mathrm{C}$ were similar at all stations (Fig. 6): the lsmean $\delta^{13} \mathrm{C}$ was highest in March and decreased from March to May or June. These trends were significant at every station (Tukey's HSD with ANOVA, $p<0.01$ ). The interannual variations of the lsmean $\delta^{13} \mathrm{C}$ values, however, were not significantly correlated between any pair of stations $(t$ test, $p>0.05$ ). In addition, the linear trends of interannual $\delta^{13} \mathrm{C}$ values were not significant ( $t$-test, $\left.p>0.05\right)$. At TB, the lsmean $\delta^{13} \mathrm{C}$ values were highest in 2010 and $2011(-18.0 \pm 0.8 \%$ and $-17.9 \pm 0.6 \%$, respectively) and lowest in $2008(-22.8 \pm 1.1 \%$ ). At IB, the $\delta^{13} \mathrm{C}$ values were highest $(-18.6 \pm 0.9 \%$ ) and lowest $(-22.7 \pm 0.9 \%$ ) in 2010 and 2014, respectively; at NN, the $\delta^{13} \mathrm{C}$ values were highest $(-19.9 \pm 0.6 \%)$ and lowest $\left(-23.1 \pm 0.8 \%\right.$ ) in 2020 and 2011 ; and at $\mathrm{WB}$, the $\delta^{13} \mathrm{C}$ values were highest $(-19.3 \pm 0.8 \%$ o in 2006 and lowest $(-21.5 \pm 0.6 \%$ ) in 2009 and 2012.

Interannual and monthly variations of lsmean $\delta^{15} \mathrm{~N}$ values were also significant (Fig. 7). The monthly lsmean $\delta^{15} \mathrm{~N}$ values increased significantly from March to April, and the values in June were similar to those in April at all four stations (Fig. 7). The values in May differed between stations. The lsmean $\delta^{15} \mathrm{~N}$ values at TB and NN were significantly lower in May than in April and June, whereas the lsmean $\delta^{15} \mathrm{~N}$ value at IB was significantly higher in May than in April and June. Because there were few measurements of $\delta^{15} \mathrm{~N}$ values at WB in May, the $\delta^{15} \mathrm{~N}$ values at WB were not significantly different in May from the other monthly values.

Interannual variations of lsmean $\delta^{15} \mathrm{~N}$ values differed between stations, with the exception of WB and IB (Fig. 7). Annual lsmean $\delta^{15} \mathrm{~N}$ values at WB and IB were significantly and positively correlated ( $t$-test, $\left.p=0.028\right)$, but there were no significant correlations between annual lsmean $\delta^{15} \mathrm{~N}$ values at other pairs of stations. At IB and WB, the lowest and second-lowest annual lsmean $\delta^{15} \mathrm{~N}$ values were observed in 2014 (4.8 $\pm 0.4 \%$ and 5.6 $\pm 0.3 \%$ at IB and WB, respectively) and in 2019 (4.4 $\pm 0.4 \%$ o

215 and $6.0 \pm 0.3 \%$ at IB and WB, respectively). At TB, the lowest annual lsmean $\delta^{15} \mathrm{~N}$ value was observed in $2008(3.9 \pm 0.3 \%)$, and the highest in $2018(7.9 \pm 0.3 \%)$ and $2019\left(7.9 \pm 0.2 \%\right.$ ). At NN, the lowest and highest annual lsmean $\delta^{15} \mathrm{~N}$ values were observed in $2013(5.3 \pm 0.5 \%)$ and $2018(8.7 \pm 0.2 \%)$, respectively.

Comparisons of annual lsmean values of $\delta^{13} \mathrm{C}$ and $\delta^{15} \mathrm{~N}$ at the same station revealed a significant positive correlation only at IB. 
https://doi.org/10.5194/os-2021-74

Preprint. Discussion started: 19 August 2021

\section{Discussion}

Calanus sinicus is one of the important secondary producers that connect primary producers with higher trophic levels in the coastal area of the Japan Sea, although C. sinicus is known to prey on heterotrophic plankton in addition to phytoplankton (Hirai et al., 2018; Yi et al., 2017; Uye and Yamamoto, 1995). The $\delta^{15} \mathrm{~N}$ values of C. sinicus $(6.9 \pm 1.2 \%$ ) are consistent with this scenario: their $\delta^{15} \mathrm{~N}$ values are intermediate between those of particulate organic matter (POM) in coastal areas of the Japan Sea (around 2-6\%) (Kogure, 2004; Antonio et al., 2012) and predatory fishes such as Japanese anchovy (8.9-11.7\%o) (Tanaka et al., 2008) and Japanese sardines $(9.4 \pm 0.7 \%$ ) (Ohshimo et al., 2019).

The $\delta^{13} \mathrm{C}$ and $\delta^{15} \mathrm{~N}$ values of $C$. sinicus at a station record the variations of the $\delta^{13} \mathrm{C}$ and $\delta^{15} \mathrm{~N}$ of the POM at the same station. The in situ environment, however, is not immediately reflected in the $\delta^{13} \mathrm{C}$ and $\delta^{15} \mathrm{~N}$ values of secondary producers. The turnover of carbon and nitrogen must also be considered. Zooplankton production has not been reported in the Japanese coastal waters of the Japan Sea, but in the Kuroshio area, Kobari et al. (2018) have reported zooplankton production to be 0.7-1.0 mg $\mathrm{C} \mathrm{m}^{-3}$ day $^{-1}$ and zooplankton dry-weight (not carbon-weight) biomass to be $9.3-13.4 \mathrm{mg} \mathrm{m}^{-3}$. If the carbon content of $C$. sinicus is half its dry weight (Omori, 1969), the reported production rate is approximately $15 \%$ of the C. sinicus biomass per day. If the metabolism of carbon is ignored, one week is necessary for turnover of the carbon of $C$. sinicus. This turnover time agrees with that of Calanus finmarchicus, 5-10 days (Mayor et al., 2011). This turnover time implies that monthly variations of the $\delta^{13} \mathrm{C}$ and $\delta^{15} \mathrm{~N}$ of $C$. sinicus correspond to monthly variations of the environmental climatology.

The monthly variations of $\delta^{13} \mathrm{C}$ and $\delta^{15} \mathrm{~N}$ were similar among the stations, with the exception of $\delta^{15} \mathrm{~N}$ in May. This similarity among the four stations likely reflected the influence of the spring phytoplankton bloom. In the southern Japan Sea, the spring phytoplankton bloom occurs from the beginning of March to the beginning of April (Kodama et al., 2018b; Ishizaka and Yamada, 2019). In Wakasa Bay, the spring bloom causes the $\delta^{15} \mathrm{~N}$ of POM to increase from spring (3-5.5\%) to summer (5.5-

240 7\%) (Antonio et al., 2012). In the Kuroshio Current, which flows through Japanese coastal waters on the Pacific side of Japan, the $\delta^{15} \mathrm{~N}$ of POM increases from winter to spring because of Rayleigh fractionation as the inorganic nitrogen concentrations in the ambient water decrease (Kodama et al., 2021). The $\delta^{15} \mathrm{~N}$ of $C$. sinicus therefore increases with the increase of the $\delta^{15} \mathrm{~N}$ of their prey. The $\delta^{15} \mathrm{~N}$ of the phytoplankton increases because of Rayleigh fractionation as their uptake of nitrate draws down the ambient nitrate concentration in the Japan Sea during the decline of the spring phytoplankton bloom.

245 In the present study, the monthly $\delta^{13} \mathrm{C}$ of $C$. sinicus declined from the early stage to the late stage of the bloom or the postbloom period. This trend has not been clearly apparent during seasonal monitoring of POM in the coastal area around Japan (Antonio et al., 2012; Kodama et al., 2021), but the $\delta^{13} \mathrm{C}$ of POM increases in the western North Pacific when the chlorophyll $a$ concentration increases (Kodama et al., 2021) and the phytoplankton are growing rapidly (Laws et al., 1995). The relationships between environmental parameters and the $\delta^{13} \mathrm{C}$ of $C$. sinicus revealed by the GLMs in this study are similar to the relationships between the $\delta^{13} \mathrm{C}$ of POM and environmental conditions in the western North Pacific (Kodama et al., 2021). The relationship between chlorophyll $a$ concentrations and the $\delta^{13} \mathrm{C}$ values of $C$. sinicus may be impacted by the turnover rate, but the monthly variations of the $\delta^{13} \mathrm{C}$ of the prey of C. sinicus may drive the monthly variations of the $\delta^{13} \mathrm{C}$ of $C$. sinicus. We 
https://doi.org/10.5194/os-2021-74

Preprint. Discussion started: 19 August 2021

also considered the possibility that the decline of the monthly $\delta^{13} \mathrm{C}$ values of $C$. sinicus during the bloom period was attributable to physiological changes of C. sinicus. Calanus sinicus is capable of storing oil in a sac (Zhou et al., 2016), and the monthly variations of $\mathrm{C} / \mathrm{N}$ ratios and $\delta^{13} \mathrm{C}$ values at our observation sites indicated that $C$. sinicus stored lipids in April. The $\delta^{13} \mathrm{C}$ values of copepods decrease with increases of their fatty acid content (Smyntek et al., 2007). This tendency was evidenced in this study by the relationship between the $\delta^{13} \mathrm{C}$ values and $\mathrm{C} / \mathrm{N}$ ratios of $C$. sinicus. The decline of $\delta^{13} \mathrm{C}$ values from March to April was therefore likely to have been the result of lipid accumulation in C. sinicus. However, the relatively low $\delta^{13} \mathrm{C}$ values of $C$. sinicus in May and June are not attributable to lipid accumulation because the $\mathrm{C} / \mathrm{N}$ ratios of $C$. sinicus were not high at that time. We suspect that lipids with a low $\delta^{13} \mathrm{C}$ that had accumulated in April were assimilated into tissues beginning in May, while the $\delta^{13} \mathrm{C}$ of the POM in the ambient water may be low in May and June comparing to April.

In the Japan Sea, the interannual variations of $\delta^{13} \mathrm{C}$ and $\delta^{15} \mathrm{~N}$ are possibly affected by 1) global-scale or regional-scale events that occur throughout the Japan Sea, and 2) local-scale events that occur in every bay. Increases of anthropogenic carbon and nitrogen inputs from the atmosphere to the ocean have been monotonically changing the $\delta^{13} \mathrm{C}$ and $\delta^{15} \mathrm{~N}$ of marine organisms on a global scale (Lorrain et al., 2020; Ren et al., 2017). In our study, however, the temporal trends of the annual lsmeans of the $\delta^{13} \mathrm{C}$ and $\delta^{15} \mathrm{~N}$ values were not significant at any station. The duration of our study was shorter than those of previous studies that have reported long-term monotonic trends. Lorrain et al. (2020) have reported that the $\delta^{13} \mathrm{C}$ values of tuna decreased monotonically by $0.12 \%$ year ${ }^{-1}$, that is $1.8 \%$ in 15 years. Such a trend would have been detectable if it had occurred at our study sites. Some previous longer-term studies of zooplankton stable isotope ratios have noted that the trends have not been strictly linear (Christensen and Richardson, 2008; Chiba et al., 2012).

Regional-scale interannual variations possibly impacted the interannual variations of the $\delta^{13} \mathrm{C}$ and $\delta^{15} \mathrm{~N}$ values of C. sinicus, but such variations were not detected in our study. Ohshimo et al. (in press) indicated the monotonic decreasing trends of $\delta^{13} \mathrm{C}$ and $\delta^{15} \mathrm{~N}$ values of small pelagic fish in the Japan Sea and the East China Sea. Much nitrate was discharged by the Changjiang River into the Japan Sea during the summer of 2013 (Kodama et al., 2017b), and lowering of surface salinity by inflow from the Changjiang River occurred in the summer or autumn of 2010, 2012, and 2015 (Kosugi et al., 2021). The spatial distribution of the impact of these interannual variations, however, differed from that of the monthly variations of the $\delta^{13} \mathrm{C}$ and $\delta^{15} \mathrm{~N}$ values of $C$. sinicus. Local-scale variations were therefore more important than global-scale trends and basin-scale variations at our study sites in the coastal area of the Japan Sea, even at stations highly impacted by human activities.

Carbon and nitrogen dynamics are closely coupled, even in coastal areas where anthropogenic impacts are high (Doney et al., 2007). Our GLM results with environmental parameters as independent variables revealed mirror-image responses of $\delta^{13} \mathrm{C}$ and $\delta^{15} \mathrm{~N}$. We therefore hypothesized that there would be a negative correlation between interannual variations of $\delta^{13} \mathrm{C}$ and $\delta^{15} \mathrm{~N}$ to the extent that they were controlled by environmental parameters such as temperature and chlorophyll $a$ concentration, but the correlation between the interannual variations of $\delta^{13} \mathrm{C}$ and $\delta^{15} \mathrm{~N}$ was not significant. The implication is that the nitrogen and carbon dynamics varied in different ways at our sites. We cannot clarify the causes of the local interannual variations, but local-scale variations have been reported in the Japan Sea. For example, at TB, where the circulation is restricted, summer phytoplankton blooms exploit nutrients delivered by rivers, but fluvial nutrient inputs have little influence on the 
https://doi.org/10.5194/os-2021-74

Preprint. Discussion started: 19 August 2021

phytoplankton blooms at IB in the mouth of Toyama Bay (Terauchi et al., 2014a; Terauchi et al., 2014b). The long-term variations of total nitrogen inputs from rivers have been increasing in Wakasa Bay (Sugimoto and Tsuboi, 2017) but decreasing in Toyama Bay (Terauchi et al., 2014b). In addition, the $\delta^{15} \mathrm{~N}$ values of riverine nitrate differ as a function of their source: fertilizer, sewage, or forest soil (Sugimoto et al., 2019). In our study, the causes of the interannual variations of the $\delta^{13} \mathrm{C}$ and $\delta^{15} \mathrm{~N}$ of $C$. sinicus were unclear, but local-scale events accounted for much of the variation.

\section{Conclusions}

We used data of a 15 -year study of the $\delta^{13} \mathrm{C}$ and $\delta^{15} \mathrm{~N}$ of the calanoid copepod C. sinicus to indirectly examine spatiotemporal variations of local ecosystems. Calanus sinicus was a "secondary" producer in the area. Monthly variations of $\delta^{13} \mathrm{C}$ and $\delta^{15} \mathrm{~N}$ were affected by spring phytoplankton blooms. The interannual variations of $\delta^{13} \mathrm{C}$ and $\delta^{15} \mathrm{~N}$ differed among the areas and showed no evidence of monotonic trends. We concluded that undocumented, local-scale events accounted for most of the changes of carbon and nitrogen dynamics in the coastal areas.

The most important and informative finding of this study is that the temporal changes of coastal carbon and nitrogen dynamics were not monotonic, and they were spatially heterogenous. Global-scale and regional-scale studies have indicated that human activities have led to temporally monotonic and spatially homogenous impacts on coastal environments and ecosystems (Halpern et al., 2008; Ono, 2021; Kodama et al., 2016; Ishizu et al., 2019), but coastal areas are not spatially homogenous. This spatial heterogeneity is a very important contributor to the high value of the ecosystem services provided by coastal areas, including their role as nursery grounds for many commercially valuable fish. Management of watersheds must be carried out at a local scale, and recruitment to local fisheries resources is sensitive to local disturbances. Global-scale and regional-scale environmental changes are very important, but local-scale changes are also important. More comparative studies that address local-scale effects are needed.

\section{Code and Data availability}

Our code and data are in Mendeley Data (http://dx.doi.org/10.17632/4z7vkn22tr.1).

\section{Author contribution}

$310 \mathrm{KN}, \mathrm{NI}, \mathrm{HM}$ and TK designed the experiments, KN, AN, SY, YK, MN, NI, HM and TK carried them out. KN, AN and TK prepared the manuscript with contributions from all co-authors.

\section{Competing interests:}

The authors declare that they have no conflict of interest. 
https://doi.org/10.5194/os-2021-74

Preprint. Discussion started: 19 August 2021

\section{Acknowledgements}

Onboard observations were conducted through RVs Mizuho-Maru and Yoko-Maru of the Japan Fisheries Research and Education Agency and Dai-Roku Kaiyo-maru of Kaiyo Engineering Co. Ltd. We appreciate captains, crews, researchers, and staffs supporting us and participating in sampling in the cruises. We also thank K. Yamada and K. Matsuda for supports of onshore experiments. The funding is provided from Fisheries Agency of Japan, Japan Fisheries Research and Education Agency to all and JSPS KAKENHI (Grant-in-Aid for Scientific Research C No. 16K07831 and 19K06198) to TK and YK.

The English in this manuscript was carefully corrected by two professional editors of ELSS, both with extensive research editing experience. One of these editors is a native English speaker.

\section{References}

Aita, M. N., Tadokoro, K., Ogawa, N. O., Hyodo, F., Ishii, R., Smith, S. L., Saino, T., Kishi, M. J., Saitoh, S.-I., and Wada, E.: Linear relationship between carbon and nitrogen isotope ratios along simple food chains in marine environments, J.

325 Plankton Res., 33, 1629-1642, https://doi.org/10.1093/plankt/fbr070, 2011.

Antonio, E. S., Kasai, A., Ueno, M., Ishihi, Y., Yokoyama, H., and Yamashita, Y.: Spatial-temporal feeding dynamics of benthic communities in an estuary-marine gradient, Estuar. Coast. Shelf. Sci., 112, 86-97, https://doi.org/10.1016/j.ecss.2011.11.017, 2012.

Chen, C.-T. A., Lui, H.-K., Hsieh, C.-H., Yanagi, T., Kosugi, N., Ishii, M., and Gong, G.-C.: Deep oceans may acidify faster

330 than anticipated due to global warming, Nat. Clim. Change, 7, 890-894, https://doi.org/10.1038/s41558-017-0003-y, 2017. Chiba, S., Sugisaki, H., Kuwata, A., Tadokoro, K., Kobari, T., Yamaguchi, A., and Mackas, D. L.: Pan-North Pacific comparison of long-term variation in Neocalanus copepods based on stable isotope analysis, Prog. Oceanogr., 97-100, 63-75, https://doi.org/10.1016/i.pocean.2011.11.007, 2012.

Christensen, J. T. and Richardson, K.: Stable isotope evidence of long-term changes in the North Sea food web structure,

335 Mar. Ecol. Prog. Ser., 368, 1-8, https://doi.org/10.3354/meps07635, 2008.

Costanza, R., d'Arge, R., de Groot, R., Farber, S., Grasso, M., Hannon, B., Limburg, K., Naeem, S., O'Neill, R. V., Paruelo, J., Raskin, R. G., Sutton, P., and van den Belt, M.: The value of the world's ecosystem services and natural capital, Nature, 387, 253-260, https://doi.org/10.1038/387253a0, 1997.

Doney, S. C.: The growing human footprint on coastal and open-ocean biogeochemistry, Science, 328, 1512-1516,

340 https://doi.org/10.1126/science.1185198, 2010.

Doney, S. C., Mahowald, N., Lima, I., Feely, R. A., Mackenzie, F. T., Lamarque, J.-F., and Rasch, P. J.: Impact of anthropogenic atmospheric nitrogen and sulfur deposition on ocean acidification and the inorganic carbon system, Proc. Natl. Acad. Sci., 104, 14580-14585, https://doi.org/10.1073/pnas.0702218104, 2007.

Duce, R. A., LaRoche, J., Altieri, K., Arrigo, K. R., Baker, A. R., Capone, D. G., Cornell, S., Dentener, F., Galloway, J.,

345 Ganeshram, R. S., Geider, R. J., Jickells, T., Kuypers, M. M., Langlois, R., Liss, P. S., Liu, S. M., Middelburg, J. J., Moore, C. M., Nickovic, S., Oschlies, A., Pedersen, T., Prospero, J., Schlitzer, R., Seitzinger, S., Sorensen, L. L., Uematsu, M., Ulloa, O., Voss, M., Ward, B., and Zamora, L.: Impacts of atmospheric anthropogenic nitrogen on the open ocean, Science, 320, 893-897, https://doi.org/10.1126/science.1150369, 2008.

Furuichi, S., Yasuda, T., Kurota, H., Yoda, M., Suzuki, K., Takahashi, M., and Fukuwaka, M.: Disentangling the effects of

350 climate and density-dependent factors on spatiotemporal dynamics of Japanese sardine spawning, Mar. Ecol. Prog. Ser., 633, $157-168,2020$.

Gruber, N., Keeling, C. D., Bacastow, R. B., Guenther, P. R., Lueker, T. J., Wahlen, M., Meijer, H. A. J., Mook, W. G., and Stocker, T. F.: Spatiotemporal patterns of carbon-13 in the global surface oceans and the oceanic suess effect, Global Biogeochem. Cycles, 13, 307-335, https://doi.org/10.1029/1999gb900019, 1999. 
https://doi.org/10.5194/os-2021-74

Preprint. Discussion started: 19 August 2021

Halpern, B. S., Walbridge, S., Selkoe, K. A., Kappel, C. V., Micheli, F., D'Agrosa, C., Bruno, J. F., Casey, K. S., Ebert, C., Fox, H. E., Fujita, R., Heinemann, D., Lenihan, H. S., Madin, E. M., Perry, M. T., Selig, E. R., Spalding, M., Steneck, R., and Watson, R.: A global map of human impact on marine ecosystems, Science, 319, 948-952, https://doi.org/10.1126/science.1149345, 2008.

Hirai, J., Hamamoto, Y., Honda, D., and Hidaka, K.: Possible aplanochytrid (Labyrinthulea) prey detected using $18 \mathrm{~S}$

360 metagenetic diet analysis in the key copepod species Calanus sinicus in the coastal waters of the subtropical western North Pacific, Plank. Benth. Res., 13, 75-82, https://doi.org/10.3800/pbr.13.75, 2018.

Hirakawa, K. and Goto, T.: Diet of larval sardine, Sardinops melanostictus in Toyama Bay, southen Japan Sea, Bull. Japan Sea Reg. Fish. Res. Lab., 46, 65-75, 1996.

Hirakawa, K., Goto, T., and Hirai, M.: Diet composition and prey size of larval anchovy, Eugraulis japonicus, in Toyama

Bay, Southern Japan Sea, Bull. Japan Sea Reg. Fish. Res. Lab., 47, 67-78, 1997.

Holm-Hansen, O., Lorenzen, C. J., Holmes, R. W., and Strickland, J. D.: Fluorometric determination of chlorophyll, Journal du Conseil, 30, 3-15, 1965.

Ishizaka, J. and Yamada, K.: Phytoplankton and Primary Production in the Japan Sea, in: Remote Sensing of the Asian Seas, edited by: Barale, V., and Gade, M., Springer International Publishing, Cham, 177-189, 10.1007/978-3-319-94067-0_9,

3702019.

Ishizu, M., Miyazawa, Y., Tsunoda, T., and Ono, T.: Long-term trends in $\mathrm{pH}$ in Japanese coastal seawater, Biogeosciences, 16, 4747-4763, https://doi.org/10.5194/bg-16-4747-2019, 2019.

Kitayama, K., Seto, S., Sato, M., and Hara, H.: Increases of wet deposition at remote sites in Japan from 1991 to 2009, Journal of Atmospheric Chemistry, 69, 33-46, https://doi.org/10.1007/s10874-012-9228-3, 2012.

375 Kobari, T., Makihara, W., Kawafuchi, T., Sato, K., and Kume, G.: Geographic variability in taxonomic composition, standing stock, and productivity of the mesozooplankton community around the Kuroshio Current in the East China Sea, Fish. Oceanogr., 27, 336-350, https://doi.org/10.1111/fog.12256, 2018.

Kodama, T., Igeta, Y., Kuga, M., and Abe, S.: Long-term decrease in phosphate concentrations in the surface layer of the southern Japan Sea, J. Geophys. Res., 121, 7845-7856, https://doi.org/10.1002/2016jc012168, 2016.

380 Kodama, T., Morimoto, H., Igeta, Y., and Ichikawa, T.: Macroscale-wide nutrient inversions in the subsurface layer of the Japan Sea during summer, J. Geophys. Res., 120, 7476-7492, https://doi.org/10.1002/2015jc010845, 2015.

Kodama, T., Nishimoto, A., Horii, S., Ito, D., Yamaguchi, T., Hidaka, K., Setou, T., and Ono, T.: Spatial and seasonal variations of stable isotope ratios of particulate organic carbon and nitrogen in the surface water of the Kuroshio, J. Geophys. Res., 126, e2021JC017175, https://doi.org/10.1029/2021jc017175, 2021.

385 Kodama, T., Wagawa, T., Iguchi, N., Takada, Y., Takahashi, T., Fukudome, K.-I., Morimoto, H., and Goto, T.: Spatial variations in zooplankton community structure along the Japanese coastline in the Japan Sea: influence of the coastal current, Ocean Sci., 14, 355-369, https://doi.org/10.5194/os-14-355-2018, 2018a.

Kodama, T., Hirai, J., Tamura, S., Takahashi, T., Tanaka, Y., Ishihara, T., Tawa, A., Morimoto, H., and Ohshimo, S.: Diet composition and feeding habits of larval Pacific bluefin tuna Thunnus orientalis in the Sea of Japan: integrated

390 morphological and metagenetic analysis, Mar. Ecol. Prog. Ser., 583, 211-226, https://doi.org/10.3354/meps12341, 2017 a. Kodama, T., Morimoto, A., Takikawa, T., Ito, M., Igeta, Y., Abe, S., Fukudome, K., Honda, N., and Katoh, O.: Presence of high nitrate to phosphate ratio subsurface water in the Tsushima Strait during summer, J. Oceanogr., 73, 759-769, https://doi.org/10.1007/s10872-017-0430-4, 2017b.

Kodama, T., Wagawa, T., Ohshimo, S., Morimoto, H., Iguchi, N., Fukudome, K. I., Goto, T., Takahashi, M., and Yasuda, T.:

395 Improvement in recruitment of Japanese sardine with delays of the spring phytoplankton bloom in the Sea of Japan, Fish. Oceanogr., 27, 289-301, https://doi.org/10.1111/fog.12252, $2018 \mathrm{~b}$.

Kogure, Y.: Stable carbon and nitrogen isotope analysis of the sublittoral benthic food web structure of an exposed sandy beach, Bull. Biogeogr. Soc. Jpn., 59, 15-25, 2004.

Kosugi, N., Hirose, N., Toyoda, T., and Ishii, M.: Rapid freshening of Japan Sea Intermediate Water in the 2010s, J.

400 Oceanogr., 77, 269-281, https://doi.org/10.1007/s10872-020-00570-6, 2021.

Laws, E. A., Popp, B. N., Bidigare, R. R., Kennicutt, M. C., and Macko, S. A.: Dependence of phytoplankton carbon isotopic composition on growth rate and [CO2]aq: Theoretical considerations and experimental results, Geochim. Cosmochim. Acta, 59, 1131-1138, https://doi.org/10.1016/0016-7037(95)00030-4, 1995. 
https://doi.org/10.5194/os-2021-74

Preprint. Discussion started: 19 August 2021

Lorrain, A., Pethybridge, H., Cassar, N., Receveur, A., Allain, V., Bodin, N., Bopp, L., Choy, C. A., Duffy, L., Fry, B.,

Goni, N., Graham, B. S., Hobday, A. J., Logan, J. M., Menard, F., Menkes, C. E., Olson, R. J., Pagendam, D. E., Point, D., Revill, A. T., Somes, C. J., and Young, J. W.: Trends in tuna carbon isotopes suggest global changes in pelagic phytoplankton communities, Global Change Biolology, 26, 458-470, https://doi.org/10.1111/gcb.14858, 2020.

Lüdecke, D.: ggeffects: Tidy Data Frames of Marginal Effects from Regression Models, Journal of Open Source Software, 3 , 772, https://doi.org/10.21105/joss.00772, 2018.

410 Mayor, D. J., Cook, K., Thornton, B., Walsham, P., Witte, U. F. M., Zuur, A. F., and Anderson, T. R.: Absorption efficiencies and basal turnover of $\mathrm{C}, \mathrm{N}$ and fatty acids in a marine Calanoid copepod, Funct. Ecol., 25, 509-518, https://doi.org/10.1111/j.1365-2435.2010.01791.x, 2011.

Nakamura, K.-i., Nishimoto, A., Yasui-Tamura, S., Kogure, Y., Nakae, M., Iguchi, N., Morimoto, H., and Kodama, T.: Data for: Stable isotope ratio of Calanus sinicus in the coastal Japan Sea", Mendeley Data, https://doi.org/10.17632/4z7vkn22tr.1,

4152021.

Nishida, K., Yasu, A., Nanjo, N., Takahashi, M., Kitajima, S., and Ishimura, T.: Microscale stable carbon and oxygen isotope measurement of individual otoliths of larvae and juveniles of Japanese anchovy and sardine, Estuar. Coast. Shelf. Sci., 245, 106946, https://doi.org/10.1016/j.ecss.2020.106946, 2020.

Ohman, M. D., Rau, G. H., and Hull, P. M.: Multi-decadal variations in stable N isotopes of California Current zooplankton,

420 Deep Sea Res. I, 60, 46-55, https://doi.org/10.1016/j.dsr.2011.11.003, 2012.

Ohshimo, S., Kodama, T., Yasuda, T., Kitajima, S., Tsuji, T., Kidokoro, H., and Tanaka, H.: Potential fluctuation of $\delta 13 C$ and $\delta 15 \mathrm{~N}$ values of small pelagic forage fish in the Sea of Japan and East China Sea, Mar. Freshwater Res., in press.

Ohshimo, S., Madigan, D. J., Kodama, T., Tanaka, H., Komoto, K., Suyama, S., Ono, T., and Yamakawa, T.: Isoscapes reveal patterns of $\delta 13 \mathrm{C}$ and $\delta 15 \mathrm{~N}$ of pelagic forage fish and squid in the Northwest Pacific Ocean, Prog. Oceanogr., 175,

425 124-138, https://doi.org/10.1016/j.pocean.2019.04.003, 2019.

Ohshimo, S., Tawa, A., Ota, T., Nishimoto, S., Ishihara, T., Watai, M., Satoh, K., Tanabe, T., and Abe, O.: Horizontal distribution and habitat of Pacific bluefin tuna, Thunnus orientalis, larvae in the waters around Japan, Bull. Mar. Sci., 93, 769-787, https://doi.org/10.5343/bms.2016.1094, 2017.

Omori, M.: Weight and chemical composition of some important oceanic zooplankton in the North Pacific Ocean, Mar.

430 Biol., 3, 4-10, https://doi.org/10.1007/bf00355587, 1969.

Ono, T.: Long-term trends of oxygen concentration in the waters in bank and shelves of the Southern Japan Sea, J. Oceanogr., https://doi.org/10.1007/s10872-021-00599-1, 2021.

Ren, H., Chen, Y. C., Wang, X. T., Wong, G. T. F., Cohen, A. L., DeCarlo, T. M., Weigand, M. A., Mii, H. S., and Sigman, D. M.: 21st-century rise in anthropogenic nitrogen deposition on a remote coral reef, Science, 356, 749-752,

435 https://doi.org/10.1126/science.aal3869, 2017.

Smyntek, P. M., Teece, M. A., Schulz, K. L., and Thackeray, S. J.: A standard protocol for stable isotope analysis of zooplankton in aquatic food web research using mass balance correction models, Limnol. Oceanogr., 52, 2135-2146, https://doi.org/10.4319/10.2007.52.5.2135, 2007.

Sugimoto, R. and Tsuboi, T.: Seasonal and annual fluxes of atmospheric nitrogen deposition and riverine nitrogen export in

440 two adjacent contrasting rivers in central Japan facing the Sea of Japan, J. Hydrol. Reg. Stud., 11, 117-125, https://doi.org/10.1016/j.ejrh.2015.11.019, 2017.

Sugimoto, R., Tsuboi, T., and Fujita, M. S.: Comprehensive and quantitative assessment of nitrate dynamics in two contrasting forested basins along the Sea of Japan using dual isotopes of nitrate, Sci. Total Environ., 687, 667-678, https://doi.org/10.1016/j.scitotenv.2019.06.090, 2019.

445 Tanaka, H., Takasuka, A., Aoki, I., and Ohshimo, S.: Geographical variations in the trophic ecology of Japanese anchovy, Engraulis japonicus, inferred from carbon and nitrogen stable isotope ratios, Mar. Biol., 154, 557-568, https://doi.org/10.1007/s00227-008-0949-4, 2008.

Terauchi, G., Tsujimoto, R., and Ishizaka, J.: Influence of river discharge on seasonal and interannual variability of remotely sensed chlorophyll- $a$ concentration in Toyama Bay, the Sea of Japan, La mer, 52, 49-60, $2014 \mathrm{a}$.

450 Terauchi, G., Tsujimoto, R., Ishizaka, J., and Nakata, H.: Preliminary assessment of eutrophication by remotely sensed chlorophyll- $a$ in Toyama Bay, the Sea of Japan, J. Oceanogr., 70, 175-184, https://doi.org/10.1007/s10872-014-0222-z, 2014b. 
https://doi.org/10.5194/os-2021-74

Preprint. Discussion started: 19 August 2021

(C) Author(s) 2021. CC BY 4.0 License.

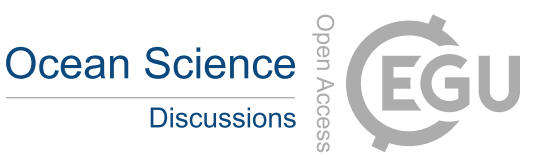

Uye, S.: Why does Calanus sinicus prosper in the shelf ecosystem of the Northwest Pacific Ocean?, ICES J. Mar. Sci., 57, 1850-1855, https://doi.org/10.1006/jmsc.2000.0965, 2000.

455 Uye, S. and Yamamoto, F.: In situ feeding of the planktonic copepod Calanus sinicus in the Inland Sea examined by the gut fluorescence method, Bull. Plankton Soc. Japan, 42, 123-139, 1995.

Yi, X., Huang, Y., Zhuang, Y., Chen, H., Yang, F., Wang, W., Xu, D., Liu, G., and Zhang, H.: In situ diet of the copepod Calanus sinicus in coastal waters of the South Yellow Sea and the Bohai Sea, Acta Oceanol. Sin., 36, 68-79, https://doi.org/10.1007/s13131-017-0974-6, 2017.

460 Zhou, K., Sun, S., Wang, M., Wang, S., and Li, C.: Differences in the physiological processes of Calanus sinicus inside and outside the Yellow Sea Cold Water Mass, J. Plankton Res., 38, 551-563, https://doi.org/10.1093/plankt/fbw011, 2016. 
https://doi.org/10.5194/os-2021-74

Preprint. Discussion started: 19 August 2021

(C) Author(s) 2021. CC BY 4.0 License.

(c) (i)

Table 1. Numbers of samples of Calanus sinicus for stable isotope analysis.

$\begin{array}{lllllll}\text { Station } & \text { March } & \text { April } & \text { May } & \text { June } & \text { Total } & 465 \\ \text { TB (Toyama Bay) } & 4 & 14 & 20 & 7 & 45 & \\ \text { IB (Iida Bay) } & 5 & 20 & 9 & 6 & 40 & \\ \text { NN (Northern part of Noto) } & 38 & 60 & 34 & 12 & 144 & \\ \text { WB (Wakasa Bay) } & 14 & 22 & 1 & 8 & 45 & \\ \text { Total } & 61 & 116 & 64 & 33 & 274 & 470\end{array}$



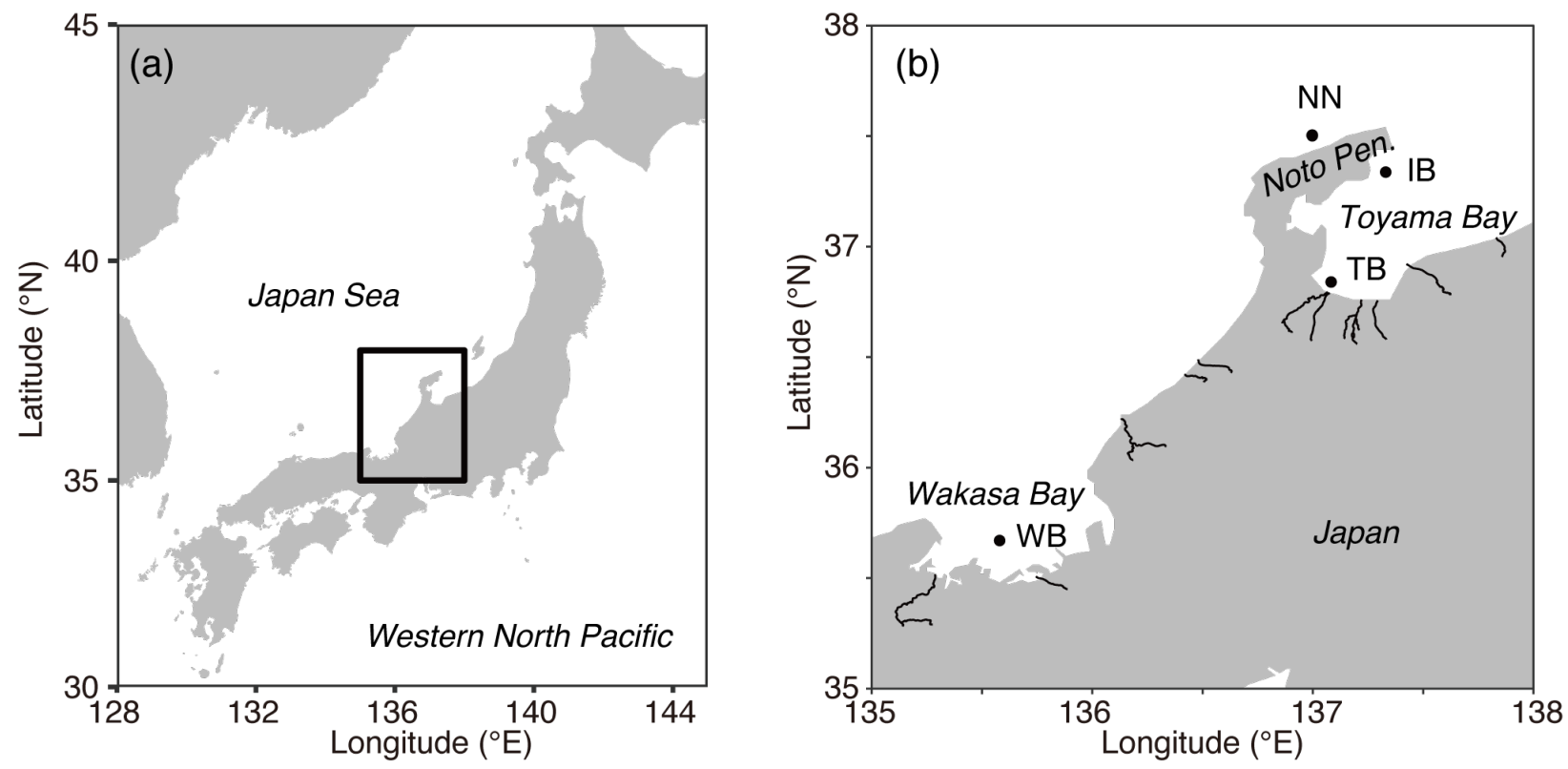

(c)

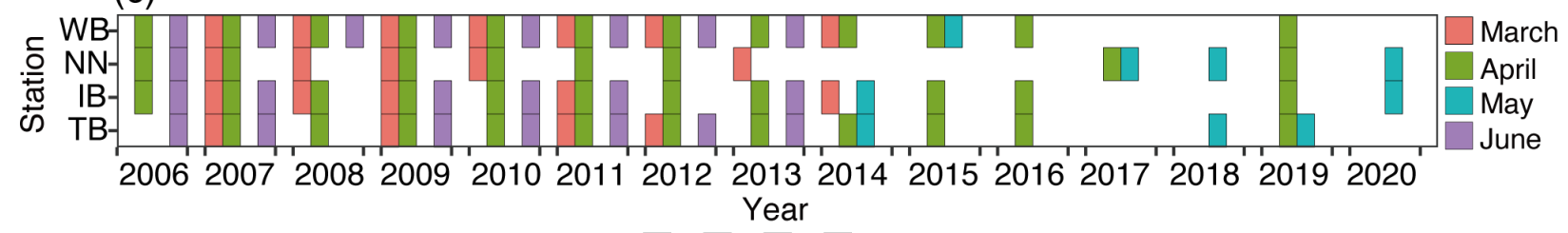

Figure 1: Sampling locations and dates. (a) Location of the study area in the Japan Sea. (b) Distribution of sampling stations (closed circles) along the Japanese coast of the Japan Sea. (c) Months and years of samplings at the four stations. The lines in (b) denote the downstream reaches of class A rivers. 
(a)
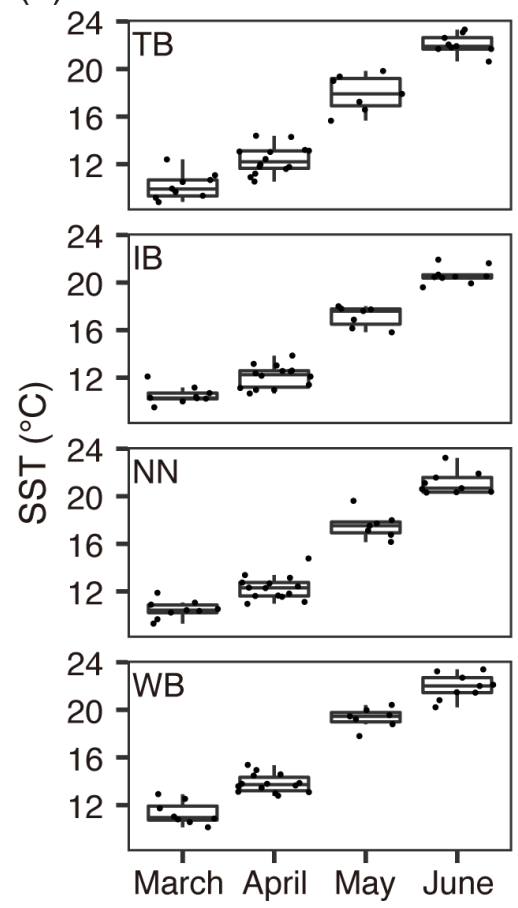

(b)
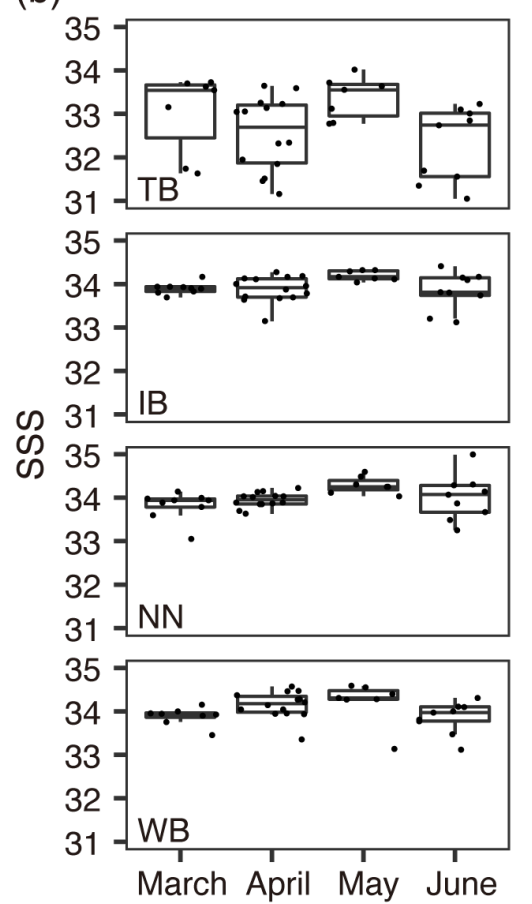

(c)
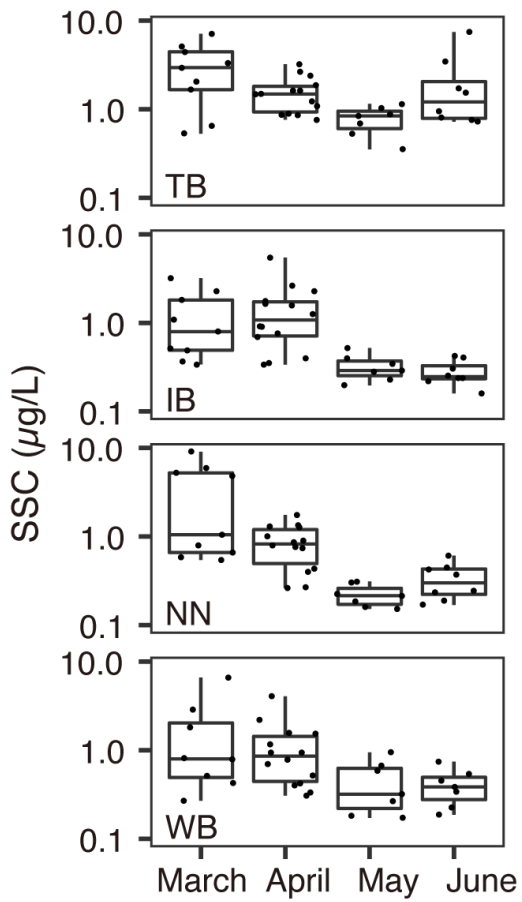

Figure 2: Variations of environmental parameters among months and stations. (a) Sea surface temperature (SST), (b) Sea surface salinity (SSS), and (c) Sea surface chlorophyll $a$ concentration (SSC). Values at TB, IB, NN, and WB are shown. Boxplots show the medians (horizontal lines within boxes), upper and lower quartiles (boxes), and quartile deviations (bars). Small points are raw data points. In (b), the lowest outlier at TB in March $(\mathrm{SSS}=28)$ is not shown. 
(a)

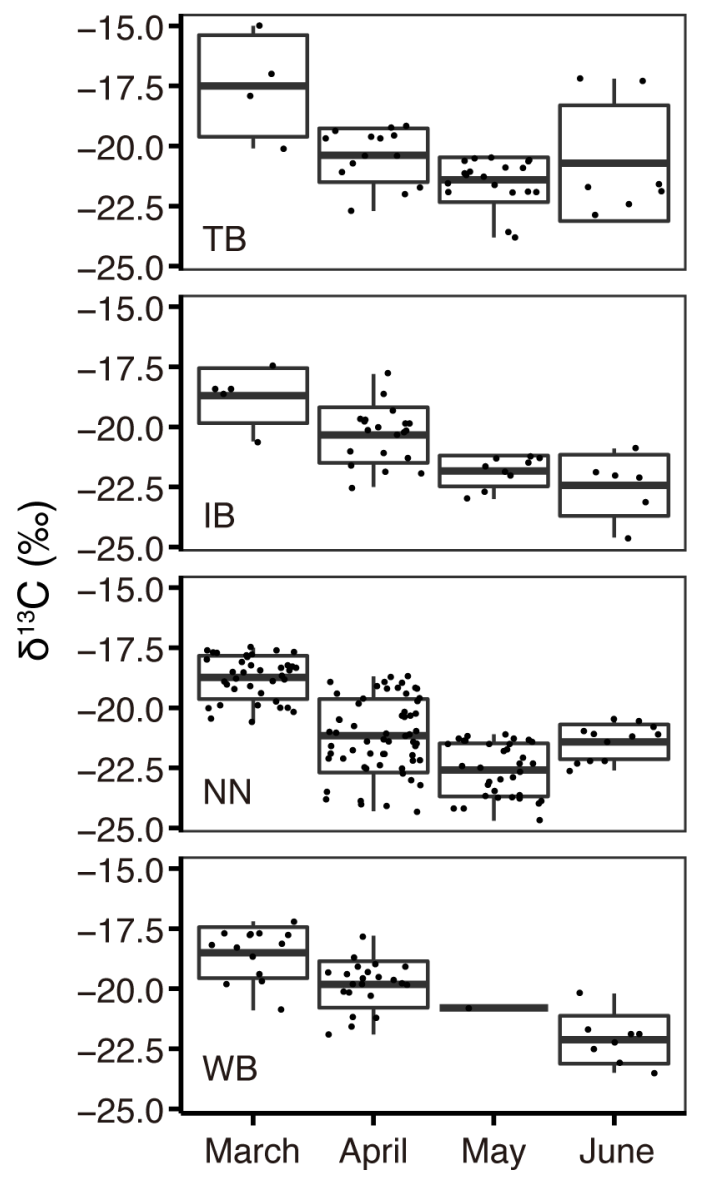

(b)
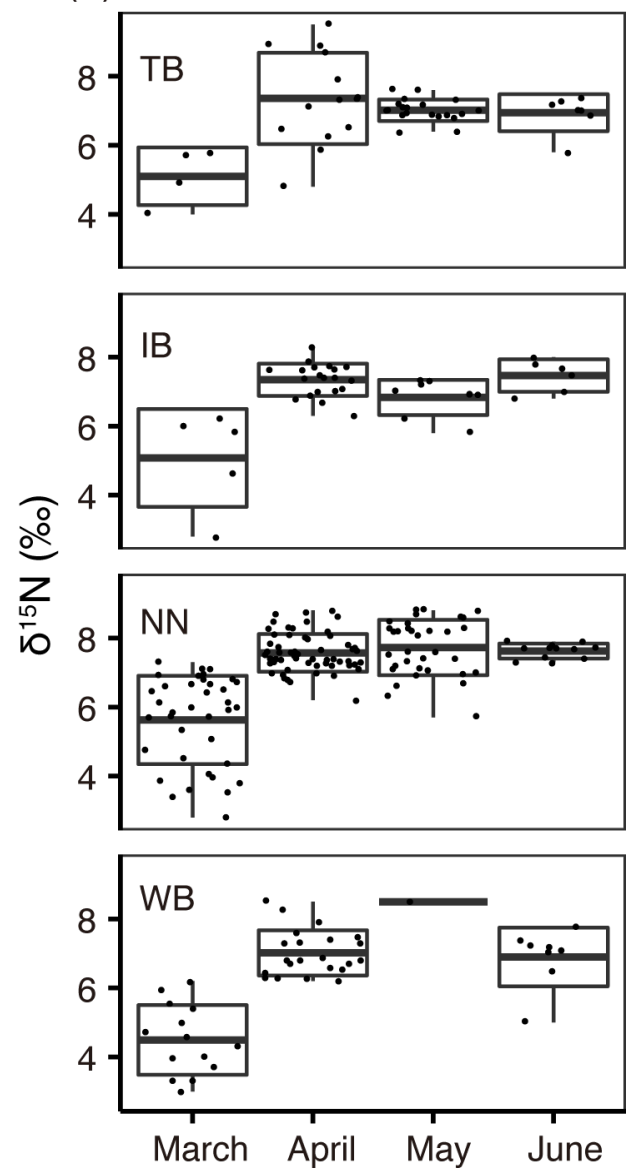

Figure 3: Variations of (a) $\delta^{13} \mathbf{C}$ and (b) $\delta^{15} \mathbf{N}$ values among months and stations. The variations at TB, IB, NN, and WB are shown. Boxplots show the means (horizontal lines within boxes), standard deviations (boxes), and maximum or minimum values (bars). Small points are raw data points. 

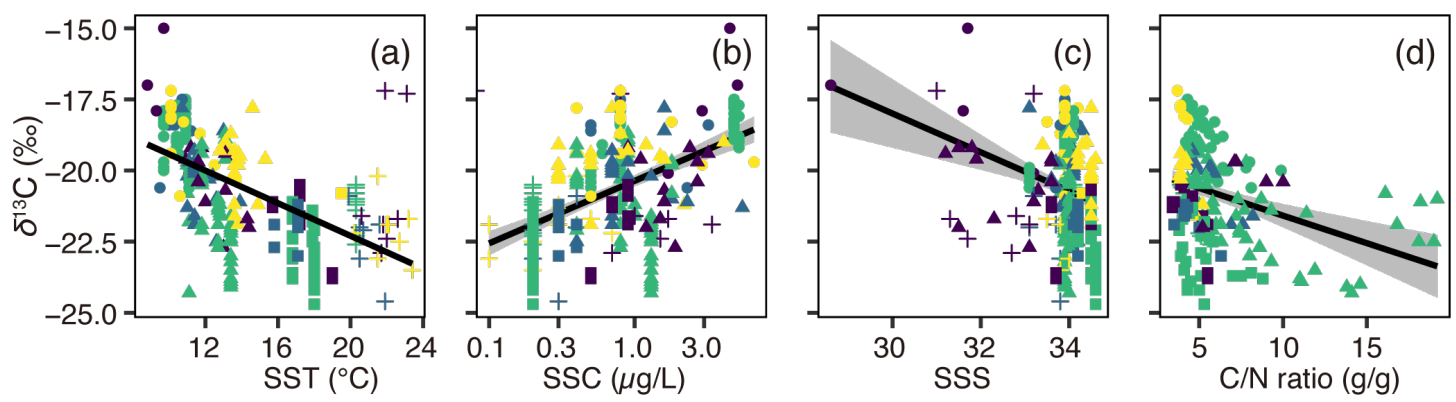

Station
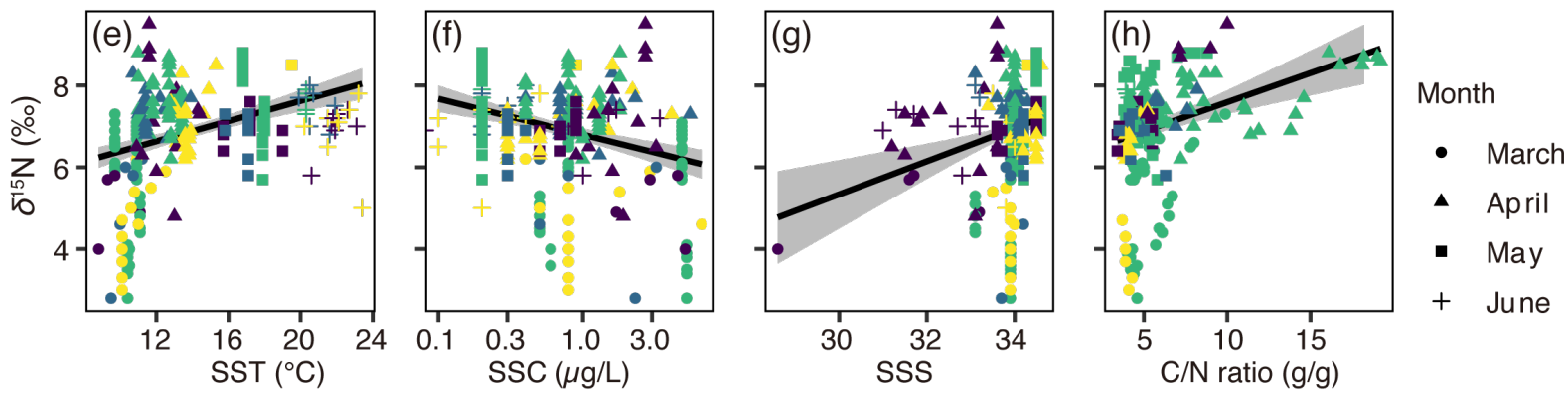

Figure 4: Relationships between (a) $\delta^{13} \mathrm{C}$ and SST, (b) $\delta^{13} \mathrm{C}$ and SSC, (c) $\delta^{13} \mathrm{C}$ and SSS, (d) $\delta^{13} \mathrm{C} \mathrm{C/N}$, (e) $\delta^{15} \mathrm{~N}$ and SST, (f) $\delta^{15} \mathbf{N}$ and SSC, (g) $\delta^{15} \mathbf{N}$ and SSS, and (h) $\delta^{15} \mathbf{N}$ and $\mathbf{C} / \mathbf{N}$. The colors and shapes of points indicate stations and sampling months, respectively. The black lines and gray shading indicate linear regression lines and $95 \%$ confidence intervals, respectively. 

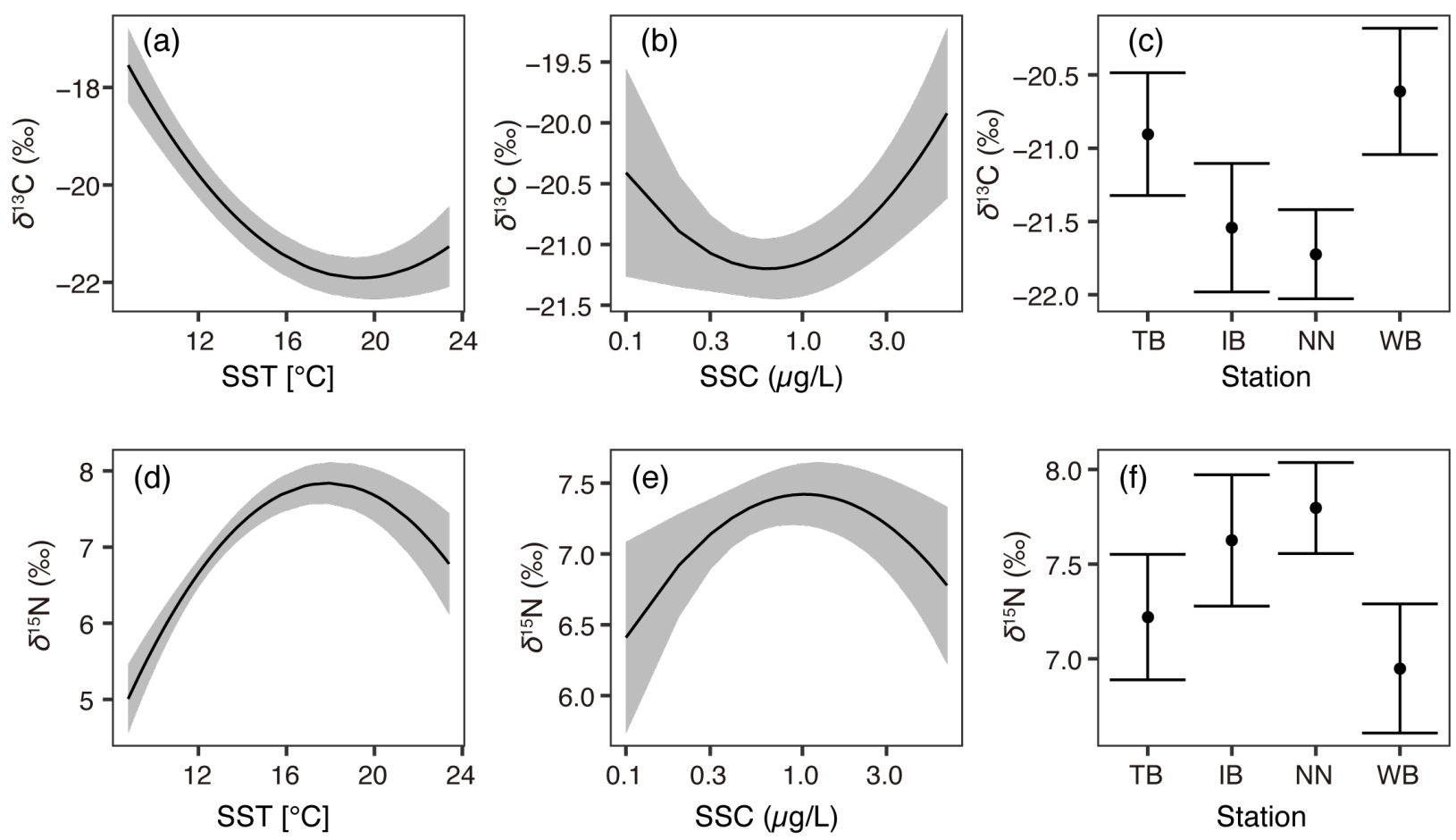

Figure 5: Responses of least-Akaike information criterion (AIC) generalized linear models (GLMs) based on least squares mean (Ismean) values. (a) $\delta^{13} \mathrm{C}$ versus SST, (b) $\delta^{13} \mathrm{C}$ versus SSC, (c) $\delta^{13} \mathrm{C}$ versus stations, (d) $\delta^{15} \mathrm{~N}$ versus SST, (e) $\delta^{15} \mathbf{N}$ versus SSC, and (f) $\delta^{15} \mathbf{N}$ versus station. Black lines with gray shading (a, b, d, and e) or closed circles with vertical

bars ( $\mathrm{c}$ and $\mathrm{f}$ ) denote the lsmean values with $95 \%$ confidence limits based on the GLMs. The numerical values of the common$\log$ transformed SSC ( $b$ and e) were re-transformed to normal values, but the axes are shown with the common-log transformed values. 
(a)
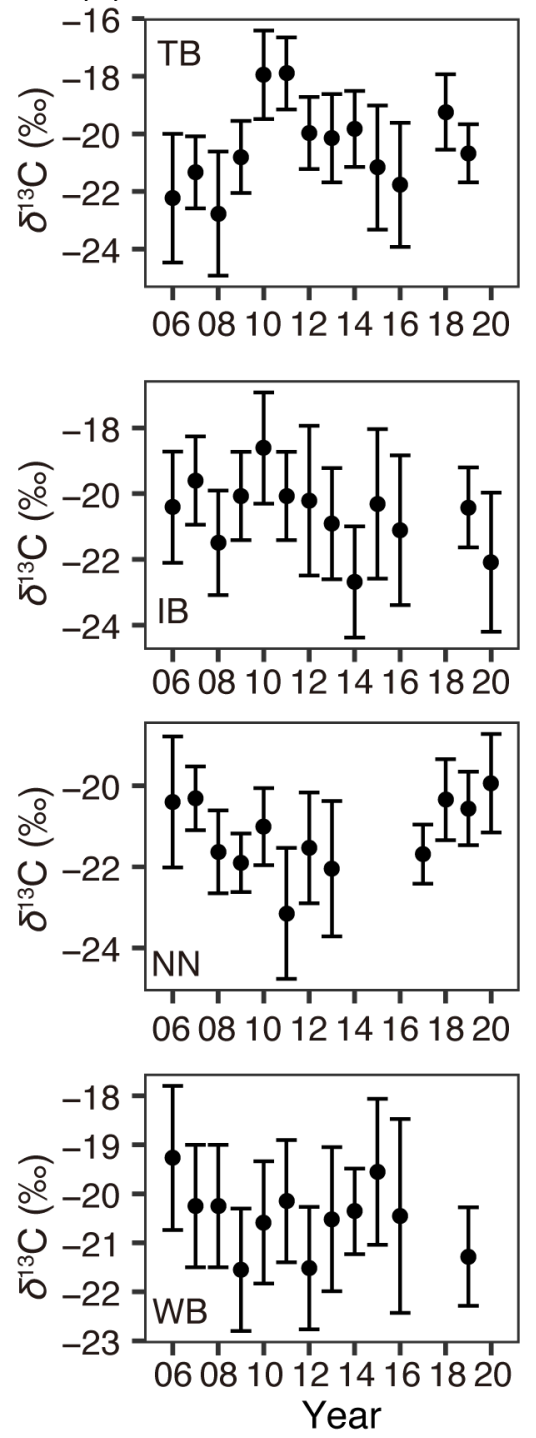

(b)
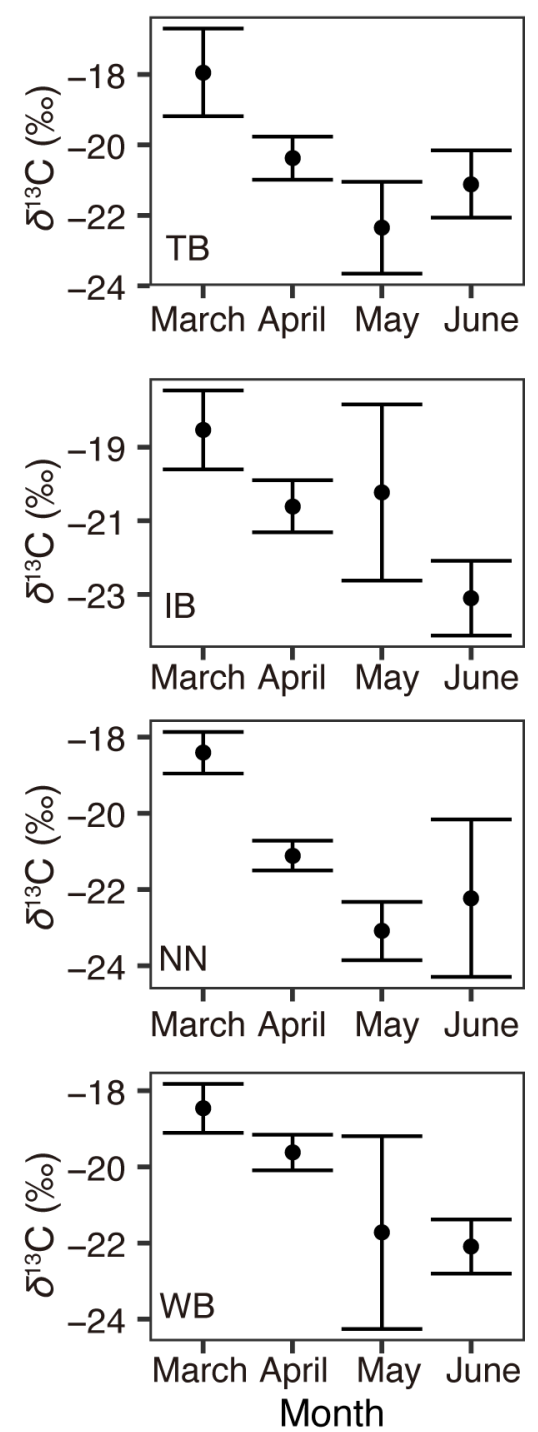

Figure 6: (a) Interannual and (b) monthly variations of Ismean $\delta^{13} \mathrm{C}$ values at TB, IB, NN, and WB. Closed circles with vertical bars denote lsmean values and $95 \%$ confidence intervals, respectively. 
(a)
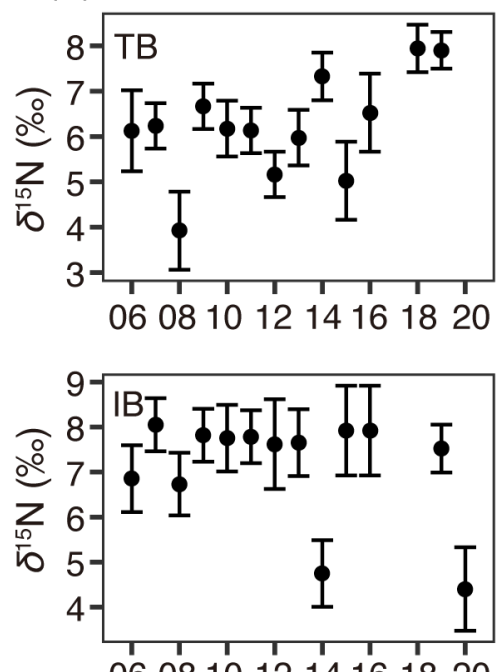

0608101214161820
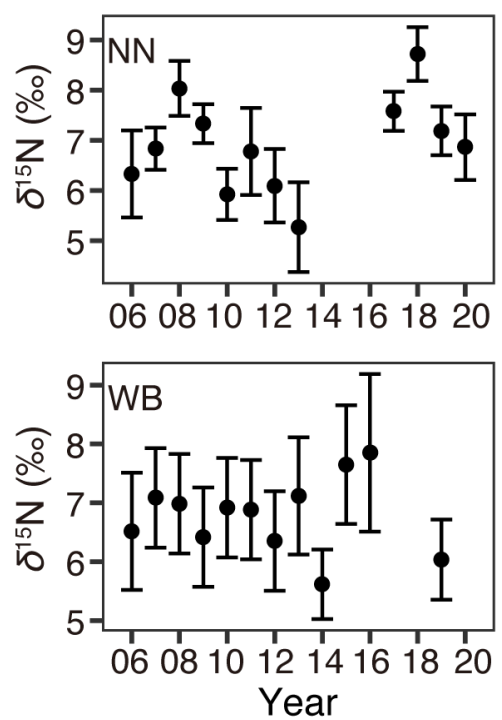

(b)
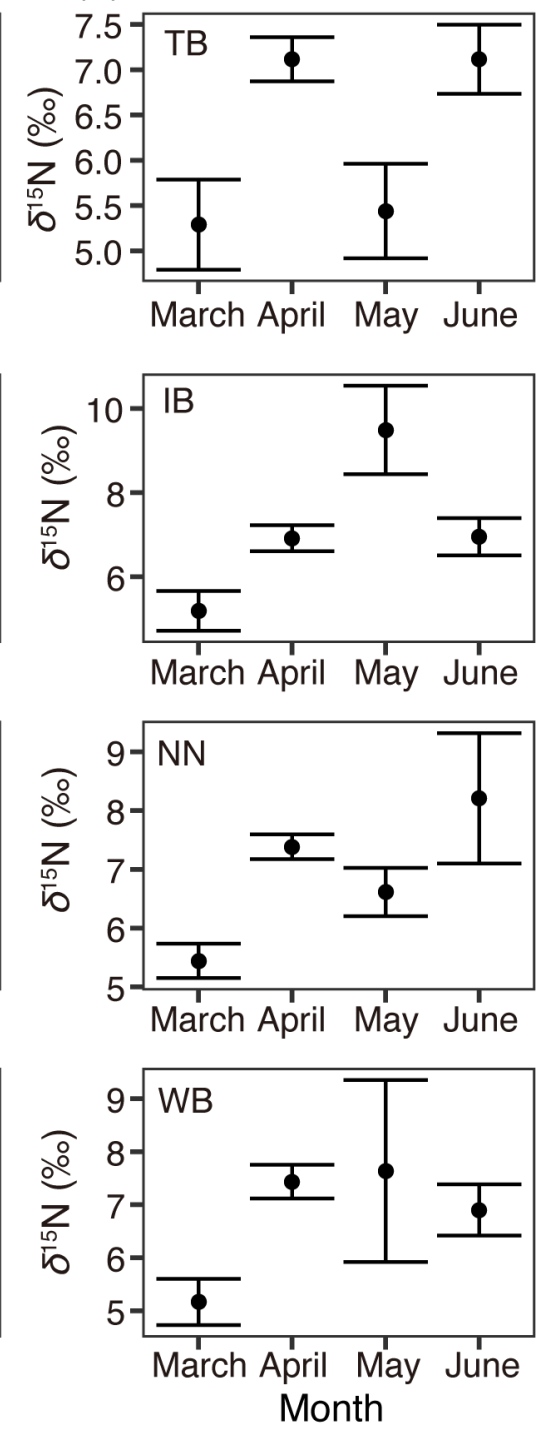

Figure 7: Same as Fig. 6, but for $\delta^{15} \mathrm{~N}$. 